\title{
The clays after heat treatment as the concrete active mineral additive
}

\author{
Olga Bazhenova ${ }^{1,{ }^{*}}$, Sofia Bazhenova, $V$. Nemirova, and Dmitriy Bazhenov \\ ${ }^{1}$ Moscow State University of Civil Engineering, Yaroslavskoe shosse, 26, Moscow, 129337, Russia
}

\begin{abstract}
Active mineral additives are one of the most common components of cement systems now. They are entered cements of increase in extent of hydration, the directed formation of structure of a cement stone from more stable hydrate phases of the lowered basicity, for the purpose of improvement of construction and technical properties of cements, by cutting of costs of fuel raw material resources for their production, giving to cements of some specific properties. In work the possibility of use as active mineral additives not only the granulated slags, but also local clays which industrially can give certain puzzolan properties are considered. It is proved that heat treatment of clay breeds significantly increases their puzzolan activity that does them suitable for use as active mineral additive instead of the domain granulated slag by production of the portland cement.
\end{abstract}

\section{Introduction}

In world practice in wide scales production of multicomponent cements is carried out. Introduction to cement of components of different look is carried out for the purpose of improving of construction and technical properties of cements, cutting of costs of fuel raw material resources for their production, giving to cements of some specific properties.

In case of introduction to the cement systems of mineral components there are both chemical, and physical and chemical processes of their interaction with cement and products of its hydration. Processes of interaction of the materials having puzzolan activity, with $\mathrm{Ca}(\mathrm{OH})_{2}$, selected in case of hydrolysis of the alit and in a smaller measure of other brick minerals belong to the main chemical processes. At the same time CSH [1] hydrosilicate with a low level of crystalizing and with the variable composition characteristic of the tobermorite are formed generally. In case of the appropriate chemical composition also formation of hydroaluminates, hydrosulfoaluminates and hydroalumosilicates is possible. The crucial role in binding of $\mathrm{Ca}(\mathrm{OH})_{2}$ is played by the vitreous and amorphized components of components containing the active $\mathrm{SiO}_{2}$ and $\mathrm{Al}_{2} \mathrm{O}_{3}$. [1,2].

Now it is recognized that the puzzolan activity is caused by thermodynamic instability of the specified components. The puzzolan activity, except chemical and mineralogical composition and structure, is influenced by a subtlety of grinding of components. The kinetics of interaction of hydrolytic lime with the active components depends also on temperature and moist conditions of solidification of [2].

\footnotetext{
*Corresponding author: sofia.bazhenova@gmail.com
} 
Binding by active additives of $\mathrm{Ca}(\mathrm{OH})_{2}$ as product of hydrolysis of brick minerals raises extent of hydration of cement that on condition of prevention of increase in water requirement and according to porosity of concrete leads to increase in its durability. Chemical binding of $\mathrm{Ca}(\mathrm{OH})_{2}$ causes corresponding change of properties of a cement stone and concrete (increase in water resistance, sulfate resistance) of [2-4].

Active mineral additives have natural and artificial origins. The first are the rocks sedimentary (diatomite, bergmeal, molding) and volcanic (pepla, tufa, pumice), the second are the domain granulated slag, fuel ash, etc.

In the last 20-25 years the tendency of the translation of a number of productions, including thermal power plant, from liquid and gaseous fuel on solid cindery fuel was outlined in world power system that has led to essential increase in volumes of the evils and slags which are formed at the same time. Collecting decades in areas of functioning of the enterprises, technogenic materials occupy the huge spaces and significantly complicate already heavy ecological situation in regions

All this does very relevant use of ashes as active mineral additive in cement. Ashes ablation represent the fine material consisting, as a rule, of parts the size from micron shares to $0,14 \mathrm{~mm}$. The structure and composition of ashes depends on the whole complex of at the same time operating factors: a look and features of the burned fuel, a subtlety of his grinding, ash-content, the chemical composition of a mineral part of fuel, temperature in a burning zone, etc. The conducted researches have shown that at the equal durability of cements without additives and with additive of ashes, the concrete mixes used for production, it isn't worse than the characteristic of concrete on cement with ashes additive on durability and frost resistance, and on water tightness - it is even significantly better, than concrete on nonadditive cement [5-6].

But nevertheless, so far, the most widespread mineral additive was the domain granulated slag. Introduction of slag in composition of cement leads to the following changes of properties knitting in comparison with cement without additives: extend terms of the beginning and end of a setting that promotes increase in storability and a remoldability of concrete mix; a set of durability of cement in early terms at natural curing is slowed down; warmth of hydration therefore such cements are recommended at construction of massive constructions decreases.

When using such cements in winter cements of conditions of curing or for production of precast concrete application the heat-methods of curing is desirable. Researches have shown that at use of the domain granulated slags the resistance of a cement stone to influence of hostile environment increases: sulfate resistance, acid resistance, alkali resistance, resistance to sea water, carbonization because of reduction in a cement stone of Sa (HE) 2 and products of hydration of the aluminate phases. Due to decrease in volume of a capillary time and increase in content of the low-main hydrosilicates of calcium concrete on such cements at comparable extent of hydration of knitting are characterized by the increased frost resistance, water resistance and water tightness [7-8].

However, use of similar additives in Russia is reduced recently that is caused by modern conditions and significant growth in transportation costs of [9]. Therefore, the question of replacement of the imported domain granulated slags with local materials, cheaper and at the same time possessing similar properties became very relevant. Works in this direction were carried out in a number of institutes and laboratories of the country. In a number of works the possibility of use as active mineral additives of the local natural and technogenic materials is shown [10-12].

But at the same time good results as the chemical composition of similar materials isn't always suitable for receiving an active component can be not always received. 
In this work the possibility of replacement at a grinding of the portland cement of such component is considered as the domain granulated slag by local clays which in industrial conditions can give certain puzzolan properties.

\section{Method}

As the studied materials used clay jurassic and moraine clay from the Afanasyevsky field which is on career overburden breed, clinker of the Voskresensky cement works and the domain granulated slag of the Lipetsk iron and steel works. The chemical composition of the used materials is presented in table 1 .

Table 1. The chemical composition of the used materials.

\begin{tabular}{|c|l|c|c|c|c|c|c|c|}
\hline $\mathrm{No}$ & Materials & $\mathrm{LOI}$ & $\mathrm{SiO}_{2}$ & $\mathrm{Al}_{2} \mathrm{O}_{3}$ & $\mathrm{Fe}_{2} \mathrm{O}_{3}$ & $\mathrm{CaO}$ & $\mathrm{MgO}$ & $\mathrm{SO}_{3}$ \\
\hline 1 & Clinker & 0,35 & 20,14 & 5,67 & 4,56 & 64,13 & 3,34 & 1,03 \\
\hline 2 & $\begin{array}{l}\text { Granulated } \\
\text { slag } \\
\text { (slag sand) }\end{array}$ & - & 39,32 & 7,41 & - & 40,56 & 9,45 & 0,84 \\
\hline 3 & Jurassic clay & 11,03 & 64,09 & 13,85 & 4,28 & 1,66 & 1,62 & 1,86 \\
\hline 4 & Moraine clay & 9,41 & 57,73 & 15,68 & 6,81 & 5,01 & 1,93 & 2,47 \\
\hline
\end{tabular}

As in clay breeds silicon dioxide and alumina are chemically connected in clay minerals and can't participate in reactions of hydration of the portland cement, for giving of puzzolan activity to them they have been subjected to heat treatment which mode has been defined on the basis of results of the differential and thermal analysis of clay breeds.

Results of DTA have shown that the beginning of decomposition of a clay component corresponds to temperature $400-4200 \mathrm{C}$, the termination - temperature 600-6500C.

Respectively clay breeds were processed at temperatures of 400, 500 and $6000 \mathrm{C}$ within 30 minutes.

The carried-out DTA of the heat treatmented samples has shown that on thermograms there is already no endoeffect at $510-5300 \mathrm{C}$, followed by loss of weight and caused by decomposition of clay minerals, at the same time there was an accurate effect demonstrating availability of untied quartz and its polymorphic transformation.

The heat treatmented clay breeds have been used as active mineral additives. For receiving cements clinker was ground in a spherical mill with additives and two-water plaster till the rest on a sieve of $00811-13 \%$.

Additives entered in number of $20 \%$, and plaster - in number of $5 \%$ over $100 \%$. For comparison as control additive used the domain granulated slag. Durability of cement was

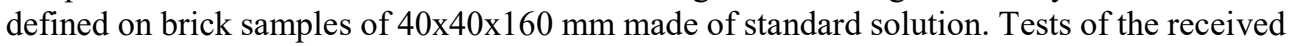
cements were carried out in accordance with the state standard specification (GOST) 310.1 - 310.3 - 76 and GOST 310.4 - 81 .

\section{Results and discussion}

Results of physic and mechanical tests of cements are given in tab. 2 and 3 (numbers of cements in tables 2 and 3 coincide). 
Table 2. Physic and mechanical properties of cements.

\begin{tabular}{|c|c|c|c|c|c|c|c|c|}
\hline \multirow[b]{2}{*}{ No } & \multicolumn{4}{|c|}{$\begin{array}{c}\text { Material composition, } \\
\% \text { of mass }\end{array}$} & \multirow{2}{*}{$\begin{array}{c}\text { Temperature } \\
\text { of heat } \\
\text { treatment, } \\
{ }^{0} \mathrm{C}\end{array}$} & \multirow{2}{*}{$\begin{array}{c}\text { Normal } \\
\text { consistency, } \\
\%\end{array}$} & \multirow{2}{*}{\multicolumn{2}{|c|}{$\begin{array}{l}\text { Setting time } \\
\text { hours-min }\end{array}$}} \\
\hline & $\dot{\bar{g}}$ & 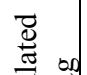 & $\cdot \frac{0}{w}>$ & $\stackrel{\Xi}{\Xi}>$ & & & & \\
\hline 1 & 100 & - & - & - & - & 24,00 & $2-25$ & $4-40$ \\
\hline 2 & 80 & 20 & & - & - & 24,00 & $3-15$ & $4-30$ \\
\hline 3 & 80 & - & 20 & - & 400 & 28,50 & $1-20$ & $4-15$ \\
\hline 4 & 80 & - & 20 & - & 500 & 28,00 & $2-10$ & $4-00$ \\
\hline 5 & 80 & - & 20 & - & 600 & 27,00 & $3-10$ & $4-00$ \\
\hline 6 & 80 & - & - & 20 & 400 & 25,25 & $2-05$ & $4-45$ \\
\hline 7 & 80 & - & - & 20 & 500 & 25,25 & $2-05$ & $3-55$ \\
\hline 8 & 80 & - & - & 20 & 600 & 25,25 & $2-30$ & $4-45$ \\
\hline
\end{tabular}

Table 3. Strength tests.

\begin{tabular}{|c|c|c|c|c|c|c|}
\hline \multirow{4}{*}{ No } & \multicolumn{6}{|c|}{ Strength limit, MPa } \\
\hline & \multicolumn{4}{|c|}{ Standard curing } & \multicolumn{2}{|c|}{ Steam treatment } \\
\hline & \multicolumn{2}{|c|}{ Bend } & \multicolumn{2}{|c|}{ Compression } & \multirow{2}{*}{ Bend } & \multirow{2}{*}{ Comp. } \\
\hline & 3 days & 28 days & 3 days & 28 days & & \\
\hline 1 & 5,7 & 7,1 & 41,1 & 53,6 & 5,1 & 40,9 \\
\hline 2 & 4,8 & 6,9 & 32,2 & 49,7 & 4,7 & 37,6 \\
\hline 3 & 5.0 & 6,5 & 31,7 & 47,2 & 4,6 & 34,4 \\
\hline 4 & 5,1 & 6,7 & 34,1 & 49,4 & 4,8 & 36,8 \\
\hline 5 & 5,3 & 7,1 & 34,9 & 49,8 & 4,8 & 37,1 \\
\hline 6 & 4,7 & 6,3 & 31,1 & 46,1 & 4,6 & 33,2 \\
\hline 7 & 5,0 & 6,3 & 31,0 & 44,7 & 4,7 & 32,2 \\
\hline 8 & 5,1 & 6,7 & 32,9 & 48,3 & 4,6 & 32,5 \\
\hline
\end{tabular}

Researches have shown that cements with additive of the heat-processed clays are characterized by a little more increased water requirement though it doesn't affect the Abram's cone demanded in accordance with GOST (state standard specification) in any way. On setting terms all cements conform to requirements of GOST 10178-85. As appears from the given results, heat treatment temperature practically doesn't affect strength indicators of the cements containing the heat-processed clay breeds in quality of active mineral additive. On the strength indicators these cements correspond to brand 400 with a large supply, otherwise the test results shown that imported granulated slag it can be replaced without prejudice to quality of cement with local additive which temperature of heat treatment doesn't exceed $500^{\circ} \mathrm{C}$.

Perhaps, the reason of it in the following. During heat treatment of clay there is a decomposition of clay minerals therefore there are active silicon dioxide and alumina reacting with the hydroxide of calcium which is emitted during hydrolysis of the alit and the forming additional amount of hydrosilicates of calcium. About it, by the way to tell, say results of determination of amount of chemically connected water during cement hydration and, also, the fact that in the hydrated cements containing the heat-processed clay the content of free hydroxide of calcium in comparison with slag-included cement decreases. 


\section{Conclusions}

By analyzing of the results of tests, and generalizing of above-mentioned, become possible to draw the following conclusions:

- using of the heat-processed clays occurs increase in extent of hydration and directed formations of structure of a cement stone from stable hydrate phases of the lowered basicity;

- heat treatment of clay breeds significantly increases their puzzolan activity that makes them suitable for use as active mineral additive instead of the domain granulated slag by production of the portland cement.

\section{References}

1. Z.B. Entin, B.E. Yudovich, NII of Cement works 107, 9-14 (2004)

2. L.I. Dvorkin, I.P Dvorkin, O.L Dvorkin, Construction mineral binder materials, 554, 201

3. V.S. Lesovik, N.A. Alfimova, et. al. Vestnik of the Belgorod STU 1, 30-33 (2009)

4. M.S. Ageeva, D.M. Sopin, G.A. Lesovik, A.A. Metrohin, N.V. Kalashnikov, V.A. Bogusevich, ARPN J. of Eng. and App. Sc. (9)8, 1381-1385 (2014)

5. L.P. Shatokhina, G.A. Zdorov, A.I. Zdorov, G.A. Fedulova, Cement 7, 29-31 (1990)

6. Z.B. Entin, L.S. Nefedova, N.V. Straljovskaya, Cem. and its app. 2, 40-46 (2012)

7. L.A. Ryabicheva, N.A. Skachko, I. Yu. Degtayr, Res. Sav. Prod. Techn. and Proc. by press. of mat. in mech. Engin. 4(21), 101-109 (2017)

8. M.S. Ageeva, D.D. Pomoshnikov, S.Z. Takhirov, et. al. The col. of sc. W. on mat. of the Inter. Sc. and pr. Conf. "Modern Society, Science and Education", 7-8 (2015)

9. The cement industry in the former Soviet Union - today: look from within, Cement and its application 1, 28-29 (2016)

10. E.A. Levchenko, V.A. Vorobchuk, E.A. Filonenko, K.A. Filonenko, News of higher educ. inst. Invest. Constr. Real est. 2 (3), 99-105 (2012)

11. V.E. Kaushansky, O.Yu. Bazhenova, L.S. Samoshchenko, Cement 3, 28-30 (2000)

12. E.A. Gamaly, K.D. Shaykhetdinov, Col.: Mat. of the 63rd sc. Conf. "YUURGU'S SCIENCE" MESRF SUSU, 113-117 (2011) 